\title{
$=$
}

\section{Um Modelo para Morrer: última etapa na construção social contemporânea da pessoa? ${ }^{1}$}

Rachel Aisengart M enezes Em janeiro de 2001, Mário Covas, então governador do estado de São Paulo, tornouse objeto de um amplo debate ao decidir "adotar total transparência no que diz respeito à sua doença", segundo um editorial do J ornal do Brasil. A exposição pública de sua doença e decadência física causaram polêmica na imprensa e na sociedade:

"A partir daí, seria dispensável vivê-la em praça pública. Os brasileiros se constrangem todos os dias com as cenas do homem que é a sombra do vigor físico esbanjado no governo do maior estado do Brasil. As cenas se sucedem e os cidadãos olham para os médicos que assistem Mário Covas, mas que, como em exemplos recentes, não assumem a responsabilidade e a autoridade de vetar esse espetáculo. ... [os médicos] sabem perfeitamente que, no estado em que se encontra, Mário Covas não tem condições de ser o árbitro de sua vontade até o último ato" (J ornal do Brasil, 17/01/01, 1ạ página).

Nos dias seguintes foram publicadas cartas de leitores, a maioria apoiando a matéria, especialmente no que tange ao poder médico e à capacidade de um doente grave tomar decisões acerca do final de sua vida. Este artigo trata do tema deste debate: uma construção surgida recentemente - a partir do final da década de 80 do século XX - sobre o morrer e o modo de participação do doente terminal neste processo. No bojo desta construção vêm sendo desenvolvidas práticas institucionais e profissionais, bem como uma extensa produção discursiva sobre as possíveis deliberações do moribundo e de sua família. Como outros fenômenos da vida social, o processo do morrer pode ser vivido de distintas formas, segundo os significados compartilhados desta experiência, o que varia segundo o momento histórico e os contextos sociais e culturais nos quais os indivíduos estão inseridos. Neste sentido a morte não se distingue das outras dimensões do universo das relações sociais e, em cada momento histórico, há uma produção de práticas e de retóricas condizentes

Campos 3:103-116, 2003. com o contexto social. 
Rachel Aisengart Menezes

\section{A MORTE TRADICIONAL E A MORTE MODERNA}

No campo das Ciências Sociais, a morte emergiu mais sistematicamente como objeto de estudos a partir da década de 60, quando surgiram as pesquisas históricas de Phillipe Ariès e de Michel Foucault, além dos trabalhos pioneiros de Norbert Elias. A partir desta produção, pode-se identificar duas configurações sociais do morrer tratadas como tipos ideais no sentido weberiano - em dois momentos históricos distintos, denominados por estes e outros autores como morte tradicional e morte moderna. A primeira foi detalhadamente investigada sob o ponto de vista histórico por Ariès (1975; 1981a), o qual considera que na sociedade hierárquica ocidental a morte de uma pessoa afetava toda a comunidade, que participava ativamente dos últimos momentos do moribundo (1975:198). Para Elias (2001), Ariès encarou o modelo de morte tradicional de forma idealizada: o morrer, comparado ao século XX, era muitas vezes mais doloroso, com um espectro menor de possibilidades de alívio dos tormentos dos agônicos. A morte era vivenciada de forma mais familiar e onipresente, menos oculta, o que não significa que se tratasse de uma experiência tranqüila e pacífica, uma vez que os sentimentos religiosos de culpa e medo do castigo eram freqüentes. O nascimento e a morte tinham caráter público: eram acontecimentos sociais, vividos na e pela comunidade, menos privatizados do que no século XX. Segundo Elias, a transformação do comportamento social - em especial entre os séculos XVIII e XX - em relação à morte é um dos aspectos do processo civilizador (2001:20).

Tanto Foucault (1979; 1994; 1995) como Ariès (1975; 1981a; 1981b) enfocaram a passagem do monopólio dos cuidados ao doente e ao moribundo, da família e dos religiosos para o médico e suas instituições. O hospital geral - como instrumento terapêutico - surge no final do século XVIII, concomitantemente à transformação no conhecimento que instituiu a racionalidade anátomo-clínica, estruturante da medicina ocidental moderna. Antes do século XVIII, o hospital era uma instituição de assistência, separação e exclusão - não do doente a ser curado, mas do pobre destinado a morrer: tratava-se de um “morredouro" (Foucault 1979: 102). No final do século XVIII, os elementos constituintes das patologias são reorganizados e a medicina passa a produzir um discurso científico sobre o indivíduo, sua saúde e doença. Na construção do paradigma referente à racionalidade anátomo-clínica ocorreu uma nova forma de integração da morte no pensamento clínico, transformando a medicina em ciência do indivíduo. De acordo com Foucault,

"Bichat fez mais do que libertar a medicina do medo da morte, ele integrou a morte em um conjunto técnico e conceitual em que ela adquiriu suas características específicas e seu valor fundamental de experiência" (1994: 167). 
Através de um processo ocorrido a partir do século $\mathrm{XV}$, as realidades e os sentimentos da infância e da família foram sendo transformados, em uma revolução profunda e gradual (Ariès 1981b:231). No século XIX, com a expansão do processo de medicalização do social, as famílias passaram a delegar os encargos dos cuidados dos seus moribundos às instituições médicas - então fortalecidas e reorganizadas. Houve, pois, um deslocamento do lugar da morte: das casas, com a participação da comunidade, para o hospital - lugar dos médicos. Como conseqüência do surgimento do hospital administrado e controlado pelos médicos surge a segunda forma de morte: a moderna. Em seus primeiros anos, o século XX assistiu ao declínio da morte tradicional, na qual

“... a morte de um homem modificava solenemente o espaço e o tempo de um grupo social que podia estenderse à comunidade toda, por exemplo à aldeia" (Ariès 1981a: 309).

A partir da 1a Grande Guerra, a morte moderna se instaura como prática social no Ocidente. Os avanços tecnológicos voltados para a guerra, a partir das duas guerras mundiais, foram também aplicados à medicina, de modo que no século XX ocorreram tanto uma racionalização do morticínio em massa como uma passagem para uma prática médica racionalizada e tecnologizada. Através da delegação social dos doentes ao saber médico e às suas instituições, a família e o enfermo foram silenciados paulatinamente. A morte passou a ser ocultada socialmente, tornando-se rotinizada e institucionalizada. A pós a década de 60 , amplia-se a produção crítica nas Ciências Sociais sobre a morte moderna, seus processos de ocultamento social e instauração do silêncio em torno da morte e de seus desígnios. Os estudos tratam também da despersonalização dos internados em hospitais, além do crescente poder médico em detrimento dos desejos do moribundo e de sua família. A morte moderna é eminentemente medicalizada, em um processo no qual este evento é inscrito em regras e rotinas institucionais, que privilegiam a competência e a eficácia médicas. Neste modelo, o moribundo encontra-se entregue às mãos do poder médico, com poucas possibilidades de acesso ao conhecimento do que se passa consigo e às opções terapêuticas. Vários autores analisaram criticamente este processo, dentre os quais Kübler-Ross (1969; 1974; 1975), com sua descrição dos estágios psicológicos por que passa o doente diante da consciência da proximidade da morte. Contudo, sua produção foi apropriada pelas equipes médicas como um modelo no qual os pacientes deveriam ser classificados, e não como um apelo à escuta de suas demandas. No campo das Ciências Sociais, Glaser e Strauss (1965; 1968) trataram da trajetória do doente no morrer, bem como das estratégias defensivas desenvolvidas pela equipe institucional em relação à morte. Nestas produções iniciais e em outras que se seguiram, emergia como problemática central o poder médico e a conseqüente desumanização, assujeitamento ou objetificação do enfermo que seu exercício implicava. 


\section{A MORTE CONTEMPORÂNEA}

Em contraposição à crescente expansão do poder médico surgiram diversos movimentos pelos direitos dos doentes, a partir da década de 70. As reivindicações abrangeram desde o direito de "morrer com dignidade" até a regulamentação da eutanásia. Por fim, houve a emergência de um discurso propondo um novo modo de prática em relação à morte em conseqüência de doença crônica terminal, no qual a relação de poder entre o doente (e sua família) e a equipe profissional seria transformada. Em 1967 surge o primeiro hospice em Londres, fundado por Saunders2 . Cerca de quinze anos após, com a epidemia de AIDS, além dos desenvolvimentos técnicos de combate ao câncer e a outras doenças degenerativas, outros hospices foram fundados, bem como serviços de assistência domiciliar paliativa. A proposta dos hospices consiste em minorar o máximo possível a dor e o desconforto do doente e, simultaneamente, possibilitar sua maior autonomia e independência. A internação em instituição deve ser efetuada somente quando não é possível a manutenção do enfermo em sua residência.

Do silêncio, ocultamento e negação passou-se, particularmente após a década de 80, à colocação da morte em discurso. Este novo modelo do morrer é nomeado pelos autores que investigam o tema como morte "neomoderna”, “pós-moderna” ou “contemporânea” (Walter 1996: 195). Equipes médicas de vários países do Ocidente voltaram-se para o estudo e pesquisa da condição do doente terminal, resultando no desenvolvimento de novas especialidades médicas, como a Clínica da Dor e a Medicina Paliativa que, em várias universidade dos Estados Unidos, Canadá e Europa tornaram-se disciplinas obrigatórias na formação de profissionais de saúde. A proposta dos Cuidados Paliativos surgiu no Brasil algumas décadas após a fundação dos primeiros hospices na Inglaterra e nos Estados Unidos. A primeira unidade de assistência paliativa foi implantada no Brasil em 1986, no Rio de J aneiro. A maior parte da bibliografia sobre o tema é originária da Inglaterra, Estados Unidos, Canadá, Austrália e França, uma vez que no Brasil a literatura ainda é muito restrita3.

A produção sobre o novo modelo de morte pode ser dividida em três áreas: a primeira é voltada a profissionais de saúde. A segunda, de divulgação ampla - como produção literária, cinematográfica, teatral, matérias divulgadas pela imprensa e circulação de mensagens através da internet, além de sites específicos sobre a temática - visa a divulgação do modelo da "boa morte" e sobre as formas de "realizá-la". Do conjunto de textos técnicos, livros de depoimentos ou de ajuda e auto-ajuda, emerge um discurso comum: o do direito do "morrer bem", com autonomia e dignidade. Na radicalização da cultura do individualismo, que valoriza a vida única e singularmente vivida, emerge o conceito da "boa morte" como a "escolhida e produzida" pelo indivíduo que está a morrer. A terceira vertente de produção sobre o tema surge cerca de trinta anos após a emergência do movimento pelo hospice e dez anos após 
Estados Unidos), refletindo sobre esta prática. Os autores destas pesquisas pertencem a distintos campos do conhecimento, como Ciências Sociais, Psicologia, Enfermagem, Antropologia, Medicina, Ética e Bioética. Na maior parte destes estudos, há concordância acerca do fato de que a visão e a prática dos profissionais de saúde foi transformada em relação ao processo de morte.

Visando compreender como se articulam nesta nova produção discursiva as deliberações em torno do "morrer bem" - como uma última etapa na construção da identidade pessoal -, serão enfocados textos advindos tanto da literatura de divulgação do ideário da "boa morte", como da recente produção reflexiva sobre o tema.

\section{TRAJ ETÓRIA PARA REALIZAÇÃO DO MODELO CONTEMPORÂNEO}

A tomada de decisões do indivíduo que está a morrer depende de três requisitos iniciais: primeiro, o conhecimento do avanço de sua doença e da proximidade da morte através de comunicação da equipe médica; segundo, a expressão dos desejos e sentimentos do paciente para as pessoas de sua relação; o terceiro requisito refere-se à escuta e atuação dos que cuidam do doente (Walter 1997:31). A realização prática destes três requisitos - visando o modelo "ideal" - é complexa, dependendo de inúmeras escolhas e envolvendo aspectos de várias ordens, dentre os quais serão abordados apenas alguns.

O primeiro aspecto que emerge nesta construção é a consciência do indivíduo da proximidade de sua morte, após um certo tempo de doença grave. Diversamente do ocultamento da situação por parte da equipe médica, como teria se passado no modelo da morte moderna, na nova modalidade os profissionais propõem um esclarecimento da situação ao paciente e à sua família. O tratamento deve ser discutido, em suas várias etapas, pelos diversos atores sociais envolvidos. Uma vez explicitados os limites da ação do médico e dos desejos do doente, o moribundo pode deliberar sobre o período de vida restante, escolher procedimentos e se despedir.

A problemática da consciência da morte constitui a dimensão central do estudo pioneiro de Glaser e Strauss (1965). Para estes autores, o conhecimento da proximidade da morte constitui um dos principais fatores explicativos dos modos de interação do doente com a equipe responsável durante o período que antecede o óbito (Herzlich 1993:11). Em sua investigação, Glaser e Strauss explicitaram uma tipologia referente à consciência da morte. Utilizando a mesma tipologia, foram realizadas duas amplas pesquisas na Inglaterra, em 1969 e em 1990, sobre as mudanças de conduta dos especialistas acerca do diálogo com o paciente (Seale, Addington-Hall, McCarthy 1997). Segundo os autores, os oncologistas foram os especialistas que mais modificaram suas atitudes neste intervalo de tempo, optando pelo diálogo franco, enquanto os demais especialistas, especialmente os neurologistas, 
mantiveram suas práticas de ocultamento da situação. Os autores do estudo concluem que, entre os doentes que receberam comunicação aberta dos profissionais de saúde, houve uma maior possibilidade de escolha do local da morte, sendo que a maioria optou por morrer em hospices ou em suas próprias residências, ao invés de desejarem morrer em hospitais. Trata-se de uma indicação de que o conhecimento do avanço da doença permitiria uma maior oportunidade de opção do modo de administração do período de vida restante (Seale et al. 1997:483).

Um episódio ilustrativo do modo de comunicação franca segundo o novo ideário é narrado por Hennezel (1995): uma operária aposentada de 70 anos foi internada na Unidade de Cuidados Paliativos, com câncer de útero com múltiplas metástases e um quadro de confusão mental. A profissional foi ao seu quarto acompanhada pela "cuidadora" que fizera a solicitação, encontrando a enferma com os cabelos desalinhados, o olhar assustado, fazendo movimentos bruscos com os braços e pernas, e falando palavras aparentemente desconexas, dentre as quais o termo morrer. Sua filha, perplexa, ao ouvir essa palavra, pedia à mãe que se acalmasse, pois ela estava na instituição para curar-se, ao que a senhora redobrava a agitação. Com a chegada das profissionais, que buscavam tranqüilizar as duas senhoras, a enferma aos poucos começou a enunciar frases, até dizer, com grande clareza: "eu vou morrer", ao que a "cuidadora" retrucou, abraçando-a: "nós estaremos aqui para Ihe acompanhar até o final". Hennezel descreve a dificuldade de aceitação da filha:

“Mamãe, não diga isto! Que vergonha!' Diante do desamparo desta filha visivelmente despreparada para uma separação, e de sua dificuldade em relação à tentativa corajosa de sua mãe no confronto com a morte, eu me aproximo. 'Sua mãe está nos dizendo o que sente. Devemos escutá-la e deixar que ela nos diga o que quer. É assim que podemos ajudá-la!' Voltando-se para sua filha que chora silenciosamente, a senhora começa a ditar suas últimas vontades. Ela quer ver todos seus filhos e netos, expressar seus últimos desejos e se despedir. Percebe-se que ela voltou a ser ela mesma, uma mulher que governa sua vida, é importante que ela delibere até o final. Sem dúvida, é sua forma de morrer com dignidade" (Hennezel 1995:43) ${ }^{4}$.

Segundo a autora e outros profissionais que militam pela causa do "morrer bem", o moribundo "sabe" que sua morte se aproxima. Cabe ao profissional facilitar sua expressão, pois, "aquele que pode dizer 'eu vou morrer', pode também ser ator de sua partida, organizando-a, como esta senhora" (Hennezel 1995:45). Talvez a dificuldade de aceitação da filha se deva à sua proximidade das práticas médicas do modelo anterior, no qual a verdade é ocultada do paciente. Com a intervenção das profissionais, as posturas da mãe e da filha modificaram-se: a filha aceitou, com tristeza, os desejos de sua mãe. Alguns dias após o episódio de agitação, a profissional retornou ao quarto da doente e ouviu o relato da cerimônia do adeus, na qual sua família estivera à sua volta. No ideário contemporâneo é através da ajuda de um profissional habilitado que um doente terminal pode permanecer como indivíduo, autônomo, independente, com desejo próprio. No caso descrito, a senhora pôde decidir e atuar como 
seus últimos desejos, é necessário um processo de negociação com a autoridade profissional e com as pessoas de suas relações.

De acordo com o recente ideário, há um segundo requisito para alcançar a "boa morte": que o moribundo expresse seus próprios desejos. Para Hennezel (1995:47) e para outros autores que divulgam o modelo, não basta que o doente terminal - em seu processo de construção de identidade pessoal - conheça seus desejos, é necessário também que ele os expresse, que seja escutado e reconhecido. Segundo Hennezel, "uma vez concluído o relato de sua vida, a pessoa pode relaxar e morrer em paz" (1995: 147). A nova proposta é percebida socialmente - pelos que militam em seu favor e pelos que já usufruíram de seus recursos - como um avanço em relação ao modelo anterior de morte. Entretanto, a prática de seu ideário não é simples, uma vez que a expressão dos sentimentos do paciente envolve outros atores sociais, por vezes com relações afetivas complexas. O caso de Paul, relatado por Hennezel, é ilustrativo. De acordo com esta autora, ao receber a visita de uma psicóloga, um doente pode reagir de várias formas, segundo o maior ou menor contato com a linguagem e os saberes psicológicos. Paul fazia parte de um meio intelectual que valorizava o falar de si. Ao perceber que o final de sua vida se aproximava, decidiu pela internação na mesma unidade de cuidados paliativos onde seu companheiro fora cuidado até morrer. Após a morte de seu companheiro, a vida não fazia mais sentido para Paul, que então interrompeu o tratamento contra a AIDS. No momento da internação o rapaz apresentava problemas neurológicos que o impediam de andar e havia perdido a visão do olho esquerdo. Antes da internação Paul organizara todos seus papéis e documentos e, a partir de então, sua esperança resumia-se em morrer o mais rapidamente possível. Em conversa com Hennezel, o doente fala de seus pais, que vieram do interior para acompanhá-lo:

“Eu não suporto eles! J amais Ihes disse que sou homossexual. Eles nunca souberam nada de minha vida, não sabem que eu vivi com alguém que morreu aqui no ano passado. Não tenho nada a dizer a eles. Agora eles vêm aqui me ver todos os dias, sentam-se e me olham com tristeza. As horas passam, pesadas, penosas, não falamos nada, eu finjo dormir, não agüento mais! Eu ia vê-los regularmente, falava de meu trabalho, de minha empresa, eles estavam orgulhosos. Nunca falei de minha vida íntima pois eles não suportariam" (Hennezel 1995:92).

Hennezel se propõe a conversar com os pais de Paul, o que é bem aceito pelo doente. No encontro com o casal, surge a dúvida sobre o modo de contágio, ao que a profissional pergunta se o casal não possui nenhuma idéia. O pai de Paul responde, envergonhado: "Às vezes, nos perguntamos se ele não é homossexual, como nunca se casou...". Hennezel responde ao casal: "Paul sofre muito por não ter conseguido contar a vocês". O pai retruca que isso não é possível e solicita à psicóloga: "não quero que ele saiba que nós sabemos." A profissional tenta demovê-lo a respeito dessa decisão. 
“É um assunto encerrado! Eu amo meu filho, é sua vida, eu a respeito, mas não quero falar sobre isto com ele.' Eu [Hennezel] olho para a mãe, em busca de uma aliada. Será que ela não sente que isto poderia ajudar seu filho? Mas o pai está decidido, não falará sobre isto com seu filho. Eu aprendi a ouvir. Sei que os acontecimentos seguem um caminho, em seu ritmo. Antes de deixar o casal, informo que Paul espera que eu the fale de sua reação. 'Ele ficará aliviado ao saber que vocês o amam e que respeitam sua vida”, digo a eles (Hennezel 1995: 95).

A intervenção mediadora da profissional é remetida a um ideário de expressão das verdades, visando a meta da "boa morte". Mas a aceitação e incorporação da prática de expressão da interioridade restringe-se a certos contextos culturais. Diversamente de seus pais, do interior do país, em sua vida em Paris Paul adquiriu um capital cultural, passando a pertencer a um universo intelectual que valoriza o cultivo de si. Psicóloga e paciente conhecem e falam o mesmo idioma da subjetividade: os dois atores consideram condição necessária à preservação da identidade até a morte, a prática de um relato da vida. Para Hennezel este relato seria um ato de reafirmação da autonomia do indivíduo, já reduzida pela doença. Uma tensão constitutiva de nossa sociedade ocidental contemporânea fica evidenciada neste caso: as duas gerações são portadoras de mensagens e valores divergentes. Há um paradoxo no fato de que a função da família moderna - uma estrutura marcadamente hierárquica - seja reproduzir sujeitos que venham a se tornar indivíduos, voltados à igualdade e à liberdade. O mandamento de produção de sujeitos autônomos implica a renúncia da própria família de origem e de seus valores, como ocorreu com Paul: adquiriu autonomia em relação à sua origem e buscou horizontes mais amplos para a construção de si. Seus pais orgulham-se de sua ascensão social e econômica, mas não compartilham do mesmo ideário, de modo que a cumplicidade idealizada por Paul (e também por Hennezel) não se realiza. Na passagem de um horizonte social regido pela atribuição para o regido pela aquisição, instaura-se a crença na construção de uma identidade individual singular. Pode-se considerar que Paul e Hennezel são representantes do que Simmel denominou de individualismo qualitativo, cujo tema central é a singularidade (1964:81).

A prática do relato da vida é remetida à construção de significados para a vida e morte do doente, como também visa propiciar aos que o cercam uma "oportunidade de crescimento". A literatura de ajuda norte-americana sobre o "morrer bem" veicula um script pessoal para seus doentes, visando uma "conclusão adequada" de seus relacionamentos, em cinco frases: "eu te perdôo; perdoe-me; obrigada; eu te amo e adeus" (Byock 1997:140). Segundo Byock, os hospices dos Estados Unidos utilizam amplamente este modelo das cinco frases, considerando que, ao expressar estas frases, o indivíduo terá condições de alcançar uma "boa morte".

Há ainda um terceiro requisito na trajetória do "morrer bem", referido à escuta e atuação dos que cercam o doente. No caso de Paul, tanto sua expressão como a atuação dos profissionais são marcados pelos saberes psicológicos referidos a um processo de busca de si. Nessa situação, a atuação dos familiares concernia à palavra, uma vez que não surgiram discordâncias relativas aos cuidados corporais. O caso de Terry, narrado por Byock, 
apresenta uma questão diversa no tocante à atuação dos que cuidaram da doente. Aos 24 anos, Terry já estava casada com Paul e era mãe, quando sofreu uma cirurgia para remoção de um rim com câncer. O médico - seguindo a proposta de comunicação franca do quadro - disse ao casal que se tratava de um tipo de câncer raro e difícil de curar. O casal recusou esse prognóstico e procurou outro oncologista, mais otimista, que recomendou quimioterapia. Com a conclusão do tratamento de Terry, o casal retomou sua vida normal, a conselho médico. Terry teve mais um casal de filhos e adotou uma menina. A família mudou-se para a cidade dos pais de Paul, onde vivia em uma grande casa. Terry dedicava-se inteiramente à casa e às crianças, e durante 6 anos viveu saudavelmente. Aos 31 anos foi constatado o retorno de sua doença: o câncer espalhou-se com rapidez, mesmo com o tratamento radioterápico. Terry passou a apresentar dores no corpo, que aumentaram progressivamente em pouco tempo. Apesar da intensidade de seu sofrimento, a doente recusava-se a utilizar qualquer medicamento analgésico potente, temendo alteração de seu estado de consciência. Após oito meses em casa, com o aumento da intensidade e freqüência das crise de dor, Terry foi encaminhada ao hospice no qual Byock trabalha. Um processo de negociação foi iniciado pelo profissional, visando o alívio da doente. Terry seguia recusando os medicamentos oferecidos, não obstante a pressão exercida pela equipe, por saber que analgésicos mais potentes causam algum grau de sedação. A doente buscava viver o mais ativamente possível, não permanecia na cama e dormia um mínimo de tempo. Segundo Byock, o casal parecia agir como se Terry não estivesse enferma: eles não abordavam o tema do avanço da doença, de modo que o médico decidiu conversar abertamente sobre a iminência da morte da paciente. DisseIhes que ela provavelmente teria mais três semanas de vida, o que chocou o casal. Terry não alterou sua decisão sobre o uso de medicações, tentou manter - dentro de suas possibilidades físicas - as atividades domésticas e iniciou o planejamento de seu funeral: a música ambiental, suas roupas e as das crianças até a escolha pela cremação de seu corpo. Seus parentes foram avisados e vieram de outros estados para se despedir. O clima era tenso com a progressiva piora das dores, até que Terry atingiu um estado de paralisia física pela dor. Sua família se revezava à beira do leito, e sofria ao vê-la com tantas dores. A equipe do hospice tentou convencer a doente da aplicação de sedativos, até que, após uma semana de negociação, conseguiu sua concordância, já que o sofrimento tornara-se insuportável. Finalmente Terry dormiu durante 30 horas, cercada de familiares e amigos. Para Byock,

“Terry não 'morreu bem' no sentido usual do termo, mas 'morreu a seu jeito': lutando por sua vida e pelo tempo de proximidade com sua família. Em seu processo de morrer, permaneceu fiel ao seu espírito e aos seus valores. Foi ao seu jeito: seu caminho único" (1997:193).

O novo modelo do morrer é explicitado no caso de Terry: se a "boa morte" não pode ser realizada, que o seja "ao jeito do indivíduo", com a manutenção da autonomia e da identidade do doente. Esta enferma optou por manter sua lucidez e consciência, o que foi respeitado pelos familiares e pela equipe profissional que a assistiu. 


\section{O MODELO CONTEMPORÂNEO: SUAS POSSIBILIDADES E LIMITES}

O modelo contemporâneo do "morrer bem" vem sendo investigado por diversos autores, que refletem sobre suas possibilidades e limites de aplicabilidade nos distintos contextos sócio-culturais. De acordo com McNamara (1999), que realizou observações etnográficas em serviços de Cuidados Paliativos australianos, a "boa morte" é um conceito idealizado e difícil de ser alcançado, de modo que propõe a morte "suficientemente boa" como definição mais viável, a partir da qual o doente teria maiores possibilidades de participação na tomada de decisões ao final da vida. Contudo, mesmo ao tomar como referência a morte "suficientemente boa", a autora constatou uma série de dificuldades de diálogo entre profissionais de saúde - a maior parte constituída por australianos formados nas convenções da biomedicina - e seus pacientes oriundos de diferentes grupos étnicos, como aborígenes ou imigrantes chineses. Assim, as possibilidades de acesso do paciente terminal à tomada de decisões da equipe de saúde podem variar. Como relata McNamara, um médico que estava morrendo de câncer conseguiu negociar com a equipe a administração de seus medicamentos, mas um aborígene não conseguiu alterar a conduta dos profissionais (1999:178). As desigualdades nos cuidados aos doentes terminais são institucionalizadas e variam de acordo com os locais nos quais os indivíduos estão morrendo. Em um contato inicial com a assistência paliativa pública, no Rio de J aneiro, pude verificar que os profissionais, no lidar com seus doentes, se defrontam frequentemente com a diversidade social. A implantação de unidades de Cuidados Paliativos brasileiras é regida pelo modelo inglês, que considera que o ideal para o doente terminal seja a permanência em sua própria residência. Contudo, nem todos os doentes acompanhados pelas unidades têm condições de permanecer em suas residências. Alguns vivem em barracos, nos quais convivem cerca de dez pessoas em espaços restritos; outros em favelas sem condições mínimas de higiene e salubridade; outros não possuem familiares que possam prestar os cuidados necessários - e podem ser enviados a asilos administrados por religiosos. Estes são os casos denominados de "sociais" pelos profissionais do serviço de Cuidados Paliativos observado. E os limites que colocam ao serviço podem ser ilustrados pela fala de um médico:

“A gente quer fazer cuidados paliativos direitinho, seguir o modelo.... mas não dá..... Esta gente nasce que nem bicho, vive que nem bicho, e a gente querendo que eles possam morrer bem, com dignidade.... não dá, eles não entendem, não há condições" (médico de um serviço público brasileiro de Cuidados Paliativos).

Além dos limites colocados por diferentes contextos econômicos, há também aspectos ideológicos a considerar. O recente ideário da "boa morte" foi desenvolvido inicialmente em países nos quais o individualismo é altamente pregnante. No Brasil, como em outras sociedades complexas, há distintas concepções de pessoa, que variam de acordo com o contexto social. Os três tipos ideais de morte - tradicional, moderna e contemporânea - 
coexistem no Brasil. Em pequenas cidades do interior do país, a perda de um membro pode ser vivida por toda a comunidade, e a identidade da pessoa encontra-se imbricada com a do grupo social ao qual pertence - de modo semelhante ao descrito por Ariès em seus estudos históricos (1975; 1981). Nos grandes centros urbanos predomina o modelo da morte moderna, no qual ocorre uma perda da identidade da pessoa, em sua trajetória de doente terminal, em virtude da crescente redução de sua autonomia e poder decisório. Já em unidades de Cuidados Paliativos regidas pelo ideário da morte contemporânea, a pessoa tem a possibilidade de constituir novas identidades ao estabelecer relações com a equipe de cuidados paliativos. Contudo, nem todos os pacientes de unidades de Cuidados Paliativos brasileiras estão informados do novo ideário e, via de regra, foram atendidos previamente por profissionais de saúde regidos pelo modelo da morte moderna, de modo que a possibilidade de participação nas tomadas de decisões apresenta-se como algo novo, a ser decodificado tanto pelo doente como por seus familiares.

Além da coexistência dos três modelos de morte, alguns limites se colocam para a realização prática do modelo contemporâneo de morte, especialmente no que se refere à postura dos profissionais de saúde acerca da tomada de decisões e da autonomia do doente terminal. Mesmo na prática dos cuidados paliativos, na qual os profissionais postulam que a morte é uma parte "natural" da vida e que deve ser aceita no momento em que chegar, há uma visão preeminente - por parte dos médicos - de que os "sintomas" do morrer devem ser tratados a qualquer custo. Para alguns profissionais, o alívio total da dor deve ser a meta dos cuidados prestados aos doentes terminais, enquanto para outros o imperativo é prosseguir tratando e atuando ativamente através do uso dos recursos terapêuticos - o que significa que o modelo não é incorporado igualmente por todos. Assim, pode haver uma tendência a valorizar mais a expressão ou a autonomia do doente. No caso de Terry, relatado por Byock, o individualismo se revela através do imperativo da idéia da manutenção da identidade pessoal - mesmo ao implicar em grande sofrimento. A reiteração do valor do indivíduo é feita em detrimento da redução do sofrimento corporal. Já em outros países, como na Inglaterra e no Brasil - que utiliza, com adaptações, o modelo de assistência paliativa inglesa - a ênfase recai sobre o controle da dor, a despeito da autonomia do paciente, o que conduz a outros dilemas. A autoridade a tomar decisões como as relativas ao alívio da dor deve ser o doente, mas muitos moribundos não se sentem satisfeitos com os efeitos colaterais da morfina. Assim, o profissional pode ser confrontado com a seguinte questão: como um doente terminal pode articular suas necessidades e desejos se sua função cognitiva está alterada pelos medicamentos? Como pode o enfermo se centrar nas tomadas de decisões se está incapacitado pela dor? A sedação terminal é prática comum nos serviços de Cuidados Paliativos ingleses, australianos e brasileiros e esta assistência ao morrer não é considerada eutanásia, pois os profissionais de saúde visam o alívio dos sintomas e não deliberadamente seqüestrar o moribundo de sua morte. Consequentemente, os limites da autoridade individual no final da vida são determinados pelos princípios éticos e morais dos vários atores envolvidos no processo do morrer. 
Rachel Aisengart Menezes

\section{NOTAS}

1 N.E.: Trabalho apresentado no Fórum de Pesquisa no16, “Antropologia da Pessoa: Processos de Individualização na Cultura Contemporânea".

2 Como não há um termo equivalente a hospice em português, utilizo sempre o original em inglês.

3 A produção brasileira sobre o tema ainda é escassa, mas há que se destacar e Dissertação de Mestrado de Neves (1998) sobre as representações do morrer em casa; a publicação organizada por Rezende (2000), baseada em um seminário realizado em Campinas; o livro de Cesar (2001), de divulgação de práticas voltadas a lidar com a morte de modo mais tranqüilo e o livro de Pessini (2001), baseado em sua Tese de Doutorado em Teologia Moral-Bioética

4 Tradução de minha autoria, como todas a seguir. 


\section{REFERÊNCIAS BIBLIOGRÁFICAS}

ARIÈS, Phillipe. 1975. Essais sur I'histoire de la mort en Occident - du moyen âge à nos jours. Paris: Éditions du Seuil. . 1981a. O homem diante da morte. Rio de J aneiro: Francisco Alves. . 1981b. História Social da Criança e da Família. Rio de J aneiro: LTC.

BYOCK, Ira. 1997. Dying well. Peace and possibilities at the end of life. New York: Riverhead Books.

CESAR, Bel. 2001. Morrer não se improvisa. São Paulo: Ed. Gaia.

ELIAS, Norbert. 2001. A solidão dos moribundos. Rio de J aneiro: J orge Zahar.

FOUCAULT, Michel. 1979. “O Nascimento do Hospital”. In Microfísica do Poder. Rio de J aneiro: Ed. Graal. 1994. O Nascimento da Clínica. Rio de J aneiro: Ed. Forense Universitária. . 1995. História da Loucura na Idade Clássica. São Paulo: Ed. Perspectiva.

GLASER, B. \&STRAUSS, A. 1965. Awareness of Dying. Chicago: Aldine. . 1968. Time for Dying. Chicago: Aldine.

HENNEZEL, Marie. 1995. La mort intime. Paris: Éditions Robert Laffont. HERZLICH, Claudine. 1993. Os encargos da morte. Rio de J aneiro: UERJ /IMS.

KÜBLER-ROSS, Elizabeth. 1969. On death and dying. New York: MacMillan. . 1974. Questions and answers on death and dying. New York: MacMillan. 1975. Death. The final stage of growth. New J ersey: Prentice-Hall.

MCNAMARA, Beverly. 1999. "A good enough death?" In Alan Petersen \&Charles Waddell (orgs). Health Matters. A Sociology of Illness, Prevention and Care. Buckingham: Open University Press.

NEVES, Ednalva M. 1998. Da morte biológica à morte cultural: um estudo sobre o morrer em casa em J oão Pessoa-PB. Dissertação de Mestrado. J oão Pessoa: UFPB/Programa de Pós-Graduação em Sociologia.

PESSINI, Leo. 2001. Distanásia. Até quando prolongar a vida? São Paulo: Ed. Centro Universitário/ São Camilo, Edições Loyola.

SEALE, Clive, ADDINGTON-HALL, J ulia, MCCARTHY, Mark. 1997. "Awareness of dying: prevalence, causes and consequences". Social Science and Medicine, vol. 45, no 3, 477-484.

SIMMEL, Georg. 1964. The Sociology of Georg Simmel. New York: The Free Press.

WALTER, Tony. 1997. The Revival of Death. New York: Routledge.

. 1996. "Facing Death without Tradition". In G. Howarth \& P.C. J upp (orgs). Contemporary issues in the Sociology of $\overline{\text { death}}$, dying and disposal. New York: MacMillan Press. 
Rachel Aisengart Menezes

\section{RESUMO}

Este artigo trata de uma construção recente acerca do morrer e do modo de participação do doente terminal neste processo. No bojo deste constructo, que data da década de 1980, vêm sendo desenvolvidas uma série de práticas institucionais e profissionais. Visando compreender como se articulam as deliberações em torno do "morrer bem" como última etapa na construção da identidade pessoal contemporânea, foram enfocados alguns textos representativos deste ideário. O modelo contemporâneo do morrer é comparado com duas configurações sociais - tratadas como tipos ideais no sentido weberiano - denominadas por diversos autores como morte "tradicional" e "moderna". O novo modelo é compreendido como resposta à "desumanização" da "morte moderna" e sua aplicação é constituída pela tentativa de resgatar determinados valores do modelo "tradicional". Estas três configurações da morte são entendidas como tipos históricos: a "morte tradicional" tende a dar lugar à "moderna" que, por sua vez, tende a ser sucedida pela modalidade contemporânea.

\section{ABSTRACT}

This paper discusses a recent construction of dying and how the terminal patient participates in this process. A number of institutional and professional practices are being developed around this construction, dated from the 1980's. Texts representatives of this view are analyzed here in order to understand how decisions are made around the idea of "dying well" as a last stage in the construction of contemporary personal identity. The contemporary model of dying is compared with two social configurations - taken here as ideal types in the Weberian sense referred to by several authors as "traditional" and "modern" deaths. This contemporary model consists of an attempt to respond to the "dehumanization" of "modern death", seeking to retrieve values existing in the "traditional" model. These three configurations of death are also considered as historical types: "traditional death" tends to be replaced by the "modern" that, in turn, is replaced by the "contemporary" form. 